\title{
Combined cycle plants as support for wind power
}

\author{
N. Afonso Moreira ${ }^{1 *}$, A. Borges ${ }^{1}$, A. Machado ${ }^{2}$ \\ ${ }^{1}$ CITAB - Universidade de Trás-os-Montes e Alto Douro, Vila Real, Portugal \\ ${ }^{2}$ Sonorgás - Departamento de I\&D, Vila Real, Portugal \\ *Tel: +351932 505 044,E-mail: nam@utad.pt
}

\begin{abstract}
The growing interest in diversifying the energy sources used, the major environmental objectives established, and the need to reduce the current European energy dependence, have been causing a growing and significant increase in betting on renewable energy sources. Thus recent years have witnessed a continuous increase of installed power from sources like solar, biomass, photovoltaic, wind, Biofuels, biogas among other. The integration of renewable energy is mainly in the production of electrical power, in which has already a significant contribution. In the group of renewable energy sources used for the production of electrical power wind is the source that has registered further progress, and is also expected, that represents in the future, large part of the electric energy produced by renewable energy sources.
\end{abstract}

Although the wind helps to meet many of the problems, it's also presents some disadvantages, or constraints. Among the best-known disadvantages associated with wind, as noise and visual impact, stands out as the major technical problems the flashing of its production. The inability to predict the production of wind, leads to problems in securing demand, as well as in network integrity.

In this scenario the Combined Cycle Gas Turbine (CCGT) stands out as a great complement to wind power. Their ability to quickly put into operation, as well as the advantages that technology and fuel used presents, makes it the optimal solution to integrate with the wind energy.

Keywords: Combined cycle plants, wind power,

\section{Introduction}

In the last decade it has been attended an increasing interest on renewable energy sources. This trend is mainly in response to the increased consumption of fossil fuels, to the problem of security of supply and still to tackle the environmental problems caused by such consumption. Alternative power plants, as the solar, biomass and wind energy are the great trends. However in the majority of the cases the alternative energies are incapable to support, alone, the existing demand, forcing then, a combination with other fossil fuels like natural gas, oil, etc.

Natural gas emerged as the best fuel to be used in partnership with renewable. Its combustion gives low emission levels of pollutants, ash free, the content of carbon monoxide (the most responsible for acid rain) is practically zero and the levels of $\mathrm{NO}_{\mathrm{x}}$ formed are well below the values of any other fossil fuel. Additional in its combustion, $\mathrm{CO}_{2}$ emissions (responsible for the greenhouse effect) are much lower than other fuels, may even make the comparison between the products of combustion and respiration of the human $\left(\mathrm{CO}_{2}\right.$ and $\left.\mathrm{H}_{2} \mathrm{O}\right)$. For this reasons natural gas is the best option to use in support to renewable energy.

Since 1990 gross electricity generation from renewable energy sources (RES) in Europe grew significantly. Among new renewable (excluding large hydropower), wind power has the largest addition to renewable energy capacity. One of the main disadvantages of wind power is that wind is very unpredictable. Strength can vary from none to storm force. Therefore, wind turbines are unable to produce a continuous amount of electricity during the time, creating problems with network stability, and uncertainty regarding the availability of energy. 
The combination of natural gas combined cycle plants and wind power is a good answer to grid stability problems and makes the whole system more secure. Gas is used as a back-up to overcome the intermittency of wind power.

\section{Renewable energy policies in Europe}

In the last decade, the number of countries that exploit renewable energy production has increased exponentially, and wind energy has been highlighted as a promising and attractive option among the other renewable energy sources.

Renewable have a long history of European policies and associated measures. Since 1986 the European Commission has listed among its objectives the promotion of community renewable energy [1]. In 1997 set the goal of achieving a target of 12\% renewable energy by 2010. Most recent measurements, as the document "AN ENERGY POLICY FOR EUROPE" [2], published in 2007, amends the targets for 20\% integration of renewable energy by 2020 and $10 \%$ integration of renewable energy in the transport.

\subsection{European policies for wind power}

The 20\% target means that more than one-third of the EU's electricity will come from renewable sources in 2020 - up from 16\% in 2006. By 2020, wind energy is expected to have overtaken hydropower as the EU's largest source of renewable electricity (Table 1).

Table 1. Renewable contribute to EU electricity consumption in 2020 [3].

\begin{tabular}{cccc}
\hline \multirow{2}{*}{ Type of energy } & 2005 & \multicolumn{2}{c}{2020 - Targets } \\
\cline { 2 - 4 } & TWh & TWh & \% \\
\hline Wind & 70,5 & 384 & 28 \\
Hydro & 346,9 & 180 & 13,1 \\
Photovoltaic & 1,5 & 250 & 18,3 \\
Biomass & 80 & 31 & 2,3 \\
Geothermal & 5,4 & 43 & 3,1 \\
Solar thermal elect. & --- & 5 & 0,4 \\
Ocean & --- & &
\end{tabular}

To achieve this objective, the EU adopted a new Renewable Directive in April 2009, which set individual targets for each member state. In response to the Directive 2009/28/EC [4] member countries in 2010 presented its National Action Plan for Renewable Energy [5]. This plan sets national targets for 2020 relating to the share of energy from renewable sources consumed in transport, power generation and heating and cooling (Figure 1). 


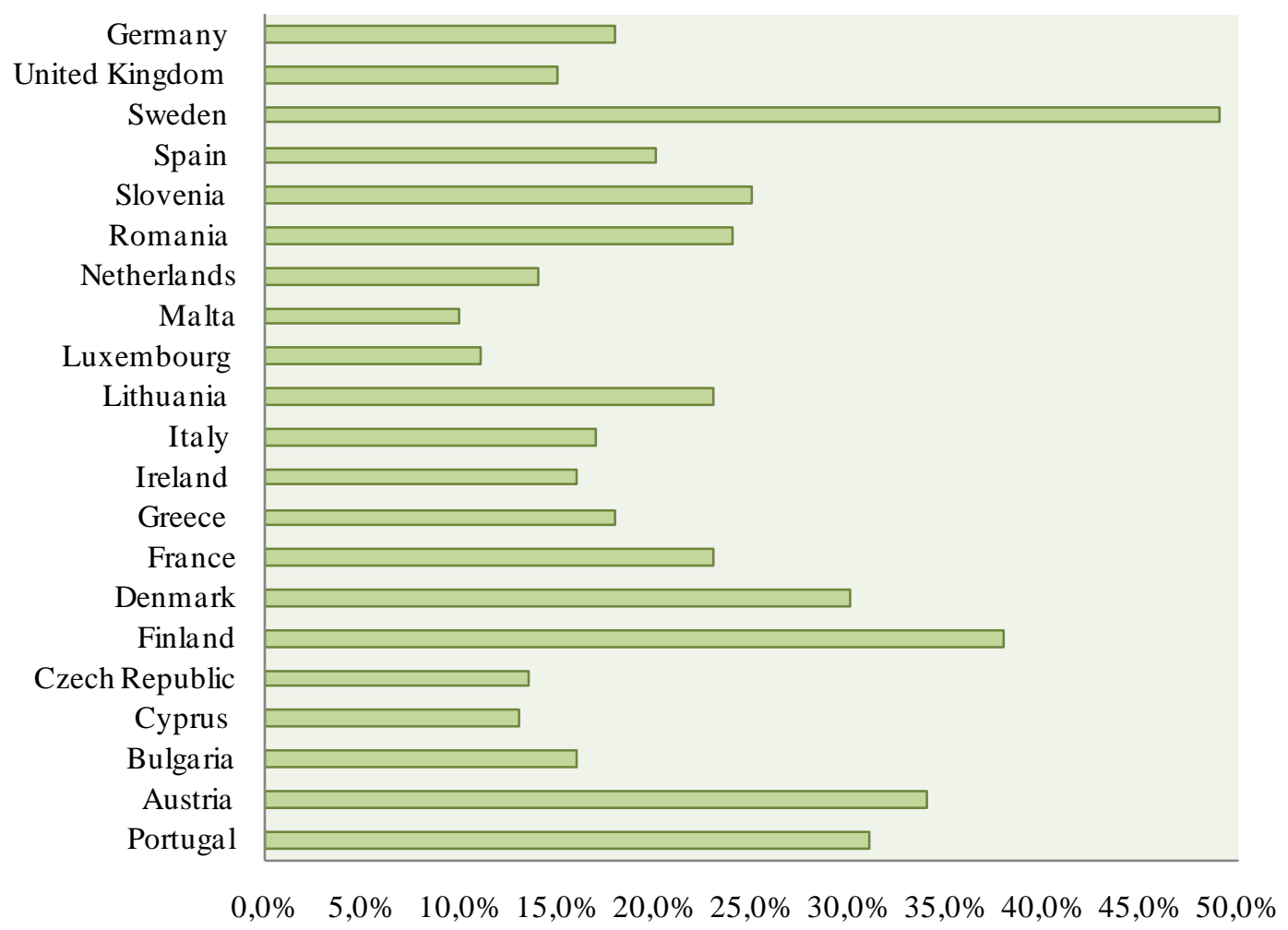

Fig. 1. Targets for Renewable Energy inclusion in final energy consumption in 2020.

With few exceptions, the field of electric energy production is the sector which foresees a greater share of energy produced by renewable energy sources. Wind energy stands out as a renewable energy source with greater participation (figure 2), and on average, excluding countries like the Czech Republic and Finland that does not estimates wind power production, the average of European countries to integrate wind power in 2020, as estimated targets, is approximately $42.3 \%$.

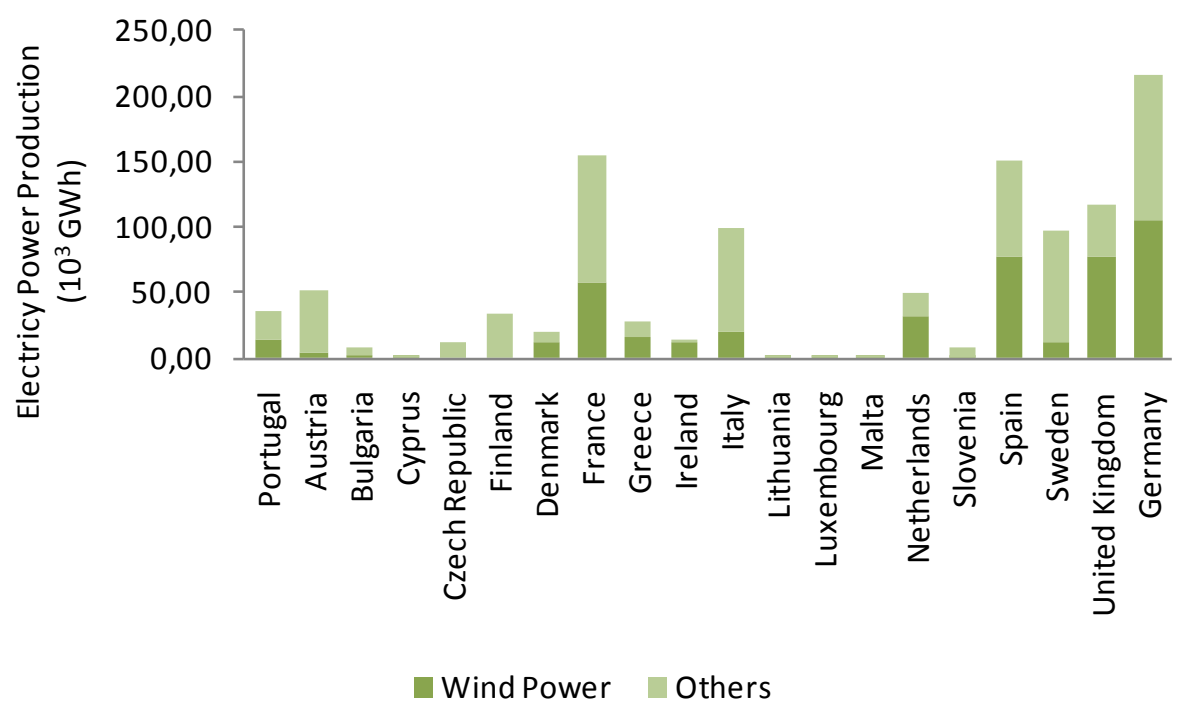

Fig. 2. Targets for Wind Power and others in electricity power production. 


\subsection{European wind energy tariffs}

In most EU member states electricity utilities now buy electricity generated from renewable sources produced by individuals and companies. Prices paid for 'self-produced' electricity is called a feed-in tariff.

Table 2. Fee-in tariffs on member state in $2010(€ / \mathrm{kWh})$ [6].

\begin{tabular}{|c|c|c|c|c|c|}
\hline Member state & $\begin{array}{l}\text { Windpower } \\
\text { 'On-shore' }\end{array}$ & $\begin{array}{c}\text { Wind power } \\
\text { 'Off-shore' }\end{array}$ & Solar PV & Biomass & Hydro \\
\hline Austria & 0.073 & 0.073 & $0.29-0.46$ & $0.06-0.16$ & $\mathrm{n} / \mathrm{a}$ \\
\hline Belgium & $\mathrm{n} / \mathrm{a}$ & $\mathrm{n} / \mathrm{a}$ & $\mathrm{n} / \mathrm{a}$ & $\mathrm{n} / \mathrm{a}$ & $\mathrm{n} / \mathrm{a}$ \\
\hline Bulgaria & $0.07-0.09$ & $0.07-0.09$ & $0.34-0.38$ & $0.08-0.10$ & 0.045 \\
\hline Cyprus & 0.166 & 0.166 & 0.34 & 0.135 & $\mathrm{n} / \mathrm{a}$ \\
\hline Czech Republic & 0.108 & 0.108 & 0.455 & $0.077-0.103$ & 0.081 \\
\hline Denmark & 0.078 & 0.078 & $\mathrm{n} / \mathrm{a}$ & 0.039 & $\mathrm{n} / \mathrm{a}$ \\
\hline Estonia & 0.051 & 0.051 & 0.051 & 0.051 & 0.051 \\
\hline Finland & $\mathrm{n} / \mathrm{a}$ & $\mathrm{n} / \mathrm{a}$ & $\mathrm{n} / \mathrm{a}$ & $\mathrm{n} / \mathrm{a}$ & $\mathrm{n} / \mathrm{a}$ \\
\hline France & 0.082 & $0.31-0.58$ & $\mathrm{n} / \mathrm{a}$ & 0.125 & 0.06 \\
\hline Germany & $0.05-0.09$ & $0.13-0.15$ & $0.29-0.55$ & $0.08-0.12$ & $0.04-0.13$ \\
\hline Greece & 0.073 & 0.073 & $0.29-0.46$ & $0.06-0.16$ & $\mathrm{n} / \mathrm{a}$ \\
\hline Hungary & $\mathrm{n} / \mathrm{a}$ & $\mathrm{n} / \mathrm{a}$ & $\mathrm{n} / \mathrm{a}$ & $\mathrm{n} / \mathrm{a}$ & $\mathrm{n} / \mathrm{a}$ \\
\hline Ireland & $0.07-0.09$ & $0.07-0.09$ & $0.34-0.38$ & $0.08-0.10$ & 0.045 \\
\hline Italy & 0.166 & 0.166 & 0.34 & 0.135 & $\mathrm{n} / \mathrm{a}$ \\
\hline Latvia & 0.108 & 0.108 & 0.455 & $0.077-0.103$ & 0.081 \\
\hline Lithuania & 0.078 & 0.078 & $\mathrm{n} / \mathrm{a}$ & 0.039 & $\mathrm{n} / \mathrm{a}$ \\
\hline Luxembourg & 0.051 & 0.051 & 0.051 & 0.051 & 0.051 \\
\hline Malta & $\mathrm{n} / \mathrm{a}$ & $\mathrm{n} / \mathrm{a}$ & $\mathrm{n} / \mathrm{a}$ & $\mathrm{n} / \mathrm{a}$ & $\mathrm{n} / \mathrm{a}$ \\
\hline
\end{tabular}

The rates of remuneration for wind energy are generally among the lowest rates of pay for electric energy produced by renewable sources in EU countries. The exceptions are Estonia, Latvia and Lithuania who practice the same tariffs for electricity produced by renewable energy sources, and Denmark, where the remuneration of the energy produced by wind is greater than the produced from biomass.

\section{Development of installed capacity and production of wind and combined cycle plants power}

During 2009, 10,526 MW of wind power was installed across Europe, of which 10,163 MW in EU countries. This represents growth in the EU of approximately 15, 5\% compared with the values of installed power in 2008 (figure 3). 


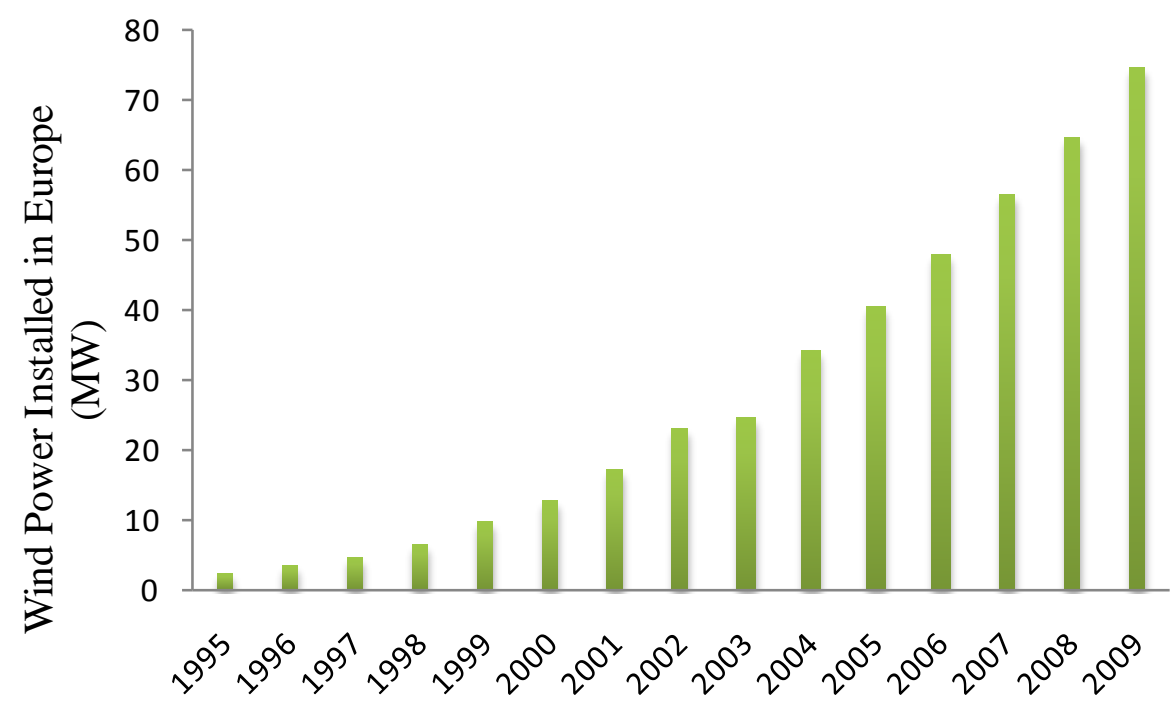

Fig. 3. Wind Power Installed in Europe [7].

The facilities in Europe are characterized by a continuous development in mature markets like Spain and Germany, along with countries like Italy, France and the UK. In 2007, production of electrical power through the wind reached a value of 104.3 GWh in the European Union [8].

Spain is the second EU country with the highest installed capacity of wind power. In 2009 it had an installed capacity of $18 \mathrm{GW}$, double the number counted in 2005 (figure 4).

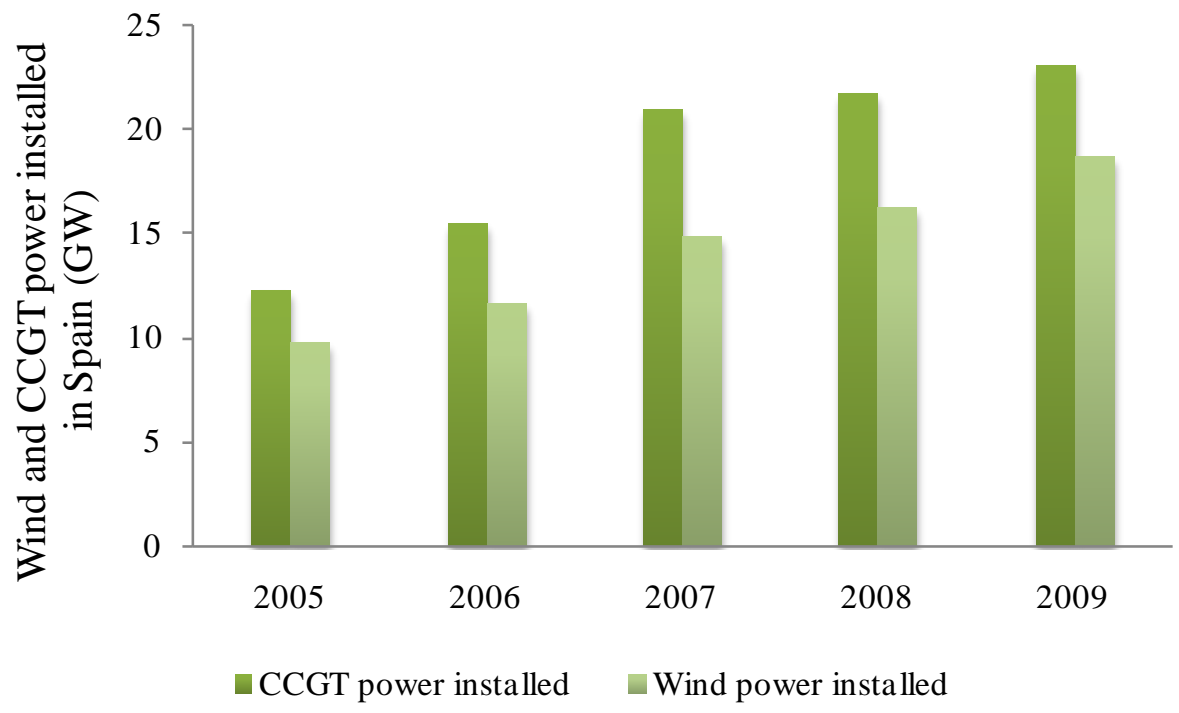

Fig. 4. CCGT and Wind Power Installed in Spain [10].

Many of the world`s electric utilities and independent power producers are turning to gas turbine combined-cycle power technology for new capacity. The major reasons for the predominance of this technology are high efficiency, moderate capital cost, low environmental impact, favorable natural gas prices and short construction schedules. Recent advances in gas turbine technology allow for a combined-cycle efficiency of almost 60 percent. The turbines used in Combined Cycle Plants are commonly fuelled with natural gas, which is found in abundant reserves in several countries. Natural gas is becoming the fuel of 
choice for private investors and consumers because it is more versatile than coal or oil and can be used in $90 \%$ of energy applications.

In the last decade, most countries concentrated their power generation investments in gasfired power plants, especially combined-cycle gas turbines (CCGT). The document "European Energy and Transport - Trends to 2030" [9], indicates that the CCGT plants accounted for about 51\% of total investment in power plants combined, between 2005 and 2010. Also according to the estimates presented in this document, in 2030 the CCGT plants will reach a total installed capacity of $145 \mathrm{GW}$ in Europe.

A country that reflects the growing interest and increasing investment in CCGT plants is Spain. In 2005 Spain had a total installed capacity of 12 GW of CCGT, in 2009 reached 23 GW, which represents an increase of $88 \%$ (figure 4).

\section{Correlation Analysis}

Although wind energy has many advantages, like being a renewable source of energy, not emissions of greenhouse gases, among other well-known advantages, also has considerable disadvantages. The disadvantages more marked are the related to visual and noise pollution caused by the same; however to technical level the biggest disadvantage of wind power is the intermittency of production. That is, wind does not present a continues production, as it is not possible to predict in advance with will be its real production.

For this reason, it is necessary to resort to so-called support system. The support system is a complementary system to the wind power, than is able to put into operation that is, to produce electrical power, in case of failure of electric power generation by wind energy, ensuring availability to demand.

The most common support systems used to support wind power plants are Combined Cycle Gas Turbine. This choice is justified by the use of a fuel that although is a fossil fuel, has great advantages when compared to the other, as well as the highly effective technology applied.

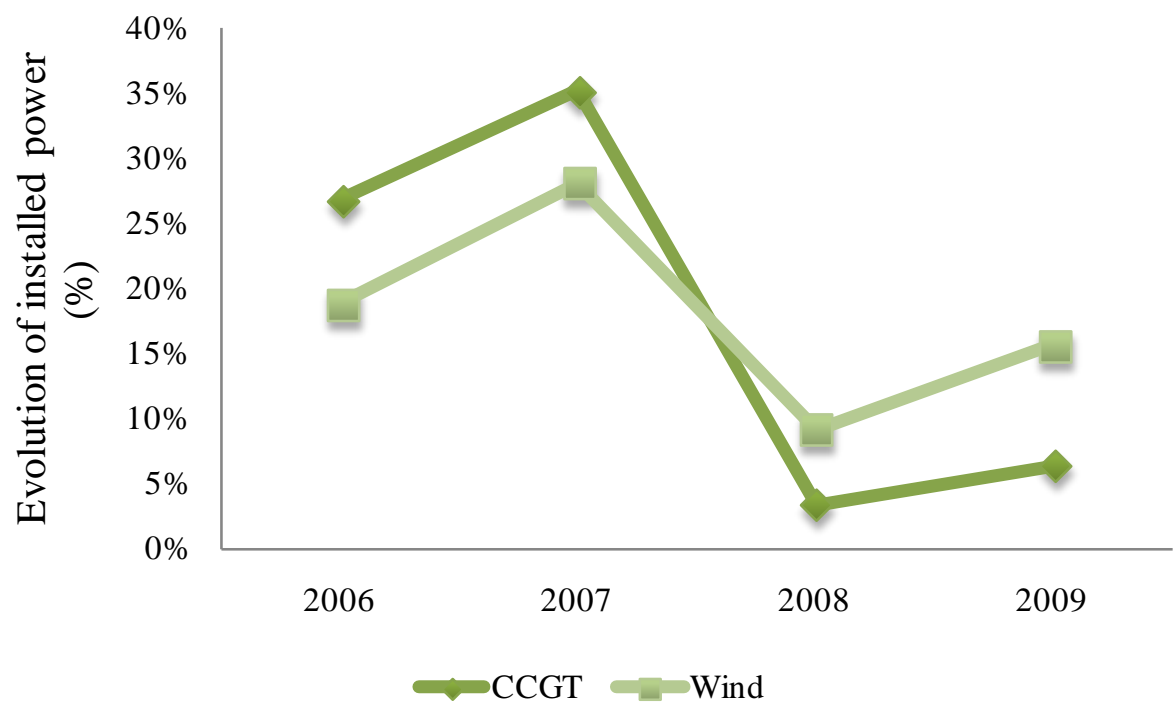

Fig. 5. CCGT and Wind evolution of installed power in Spain [10]. 
As we can see by the analysis of figure 5, the evolution of installed power to CCGT and wind power is very similar. Both forms of energy have a significant increase of installed power to the scheduled between 2006/07 and 2008/09, and both show a decrease in the growth of installed capacity in 2008.

In the year 2007, which corresponded to the years where there was a greater increase of installed power, CCGT reached a total installed capacity of $20 \mathrm{GW}$, corresponding to an increase of $5.5 \mathrm{GW}$ compared to the previous period, and the energy wind power grew by 3.2 $\mathrm{GW}$, reaching a total of $14.8 \mathrm{GW}$.

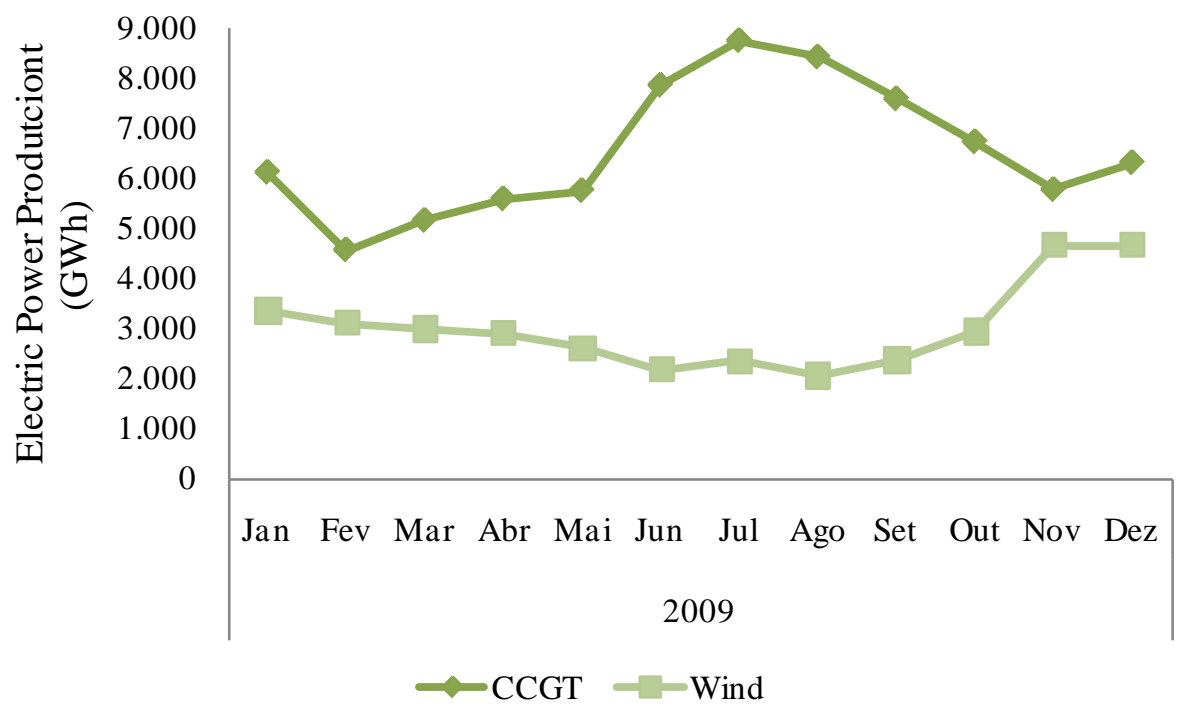

Fig. 6. CCGT and Wind electric power production in Spain [11].

As we can see by the analysis of the previous figure (Fig. 6) the electricity produce by CCGT follows the production of electric power by wind. That is, whenever there is a decrease in wind generation, the CCGT start working to remedy this breach. With the increase of electricity generation by wind, CCGT production decreases.

Thus the intermittency of electricity generation by wind does not because failures in the availability of energy and do not create problems in the network integrity.

\section{Development Perspectives}

According to estimates the installed capacity of wind power will tend to continue to increase. The figures for Europe are that the production of electricity by wind power to reach $477 \mathrm{TWH}$ in 2020.

Assuming that the trends are maintained, the increase in installed capacity of CCGT will also maintain its growth trend, and is also expected that due to the development of technology associated with CCGT this increase will be even higher than expected. With current technology, the CCGT are already the best option to serve to support the production of other renewable energy sources, specifically through the production of wind energy.

\section{References}

[1] Official Journal C 241, 09/25/1986 p. 0001 - 0003; 
[2] COM (2007) 1 final; 2007;

[3] European Renewable Technology Roadmap 2008;

[4] Directive 2009/28/EC of the European Parliament and the Council of 23 April 2009

[5] http://ec.europa.eu/energy/renewables/transparency_platform/action_plan_en.htm

[6] Price for Renewable Energies in Europe; Report 2009; European Renewable Energies Federation.

[7] Wind in power - 2009 European statistics; The European Wind Energy Association; February 2010

[8] European Environment Agency; 2008

[9] European Energy and Transport - Trends to 2030; European Commission; DirectorateGeneral for Energy and Transport; 2007.

[10] El sistema eléctrico espanõl; RED ELÉCTRICA DE ESPANÃ; 2010

[11] Boletin Mensual; RED ELÉCTRICA DE ESPANÃ; 2010 